\title{
Effects of caffeine abstinence on adenosine induced coronary flow reserve quantified on phase contrast velocity encoded MRI of the coronary sinus
}

\author{
Marcus Carlsson*1, Karin Markenroth ${ }^{2}$, Freddy Stahlberg ${ }^{3}$ and \\ Hakan Arheden ${ }^{1}$
}

Address: ${ }^{1}$ Dep of Clinical Physiology, Lund, Sweden, ${ }^{2}$ Philips Medical System, Lund, Sweden and ${ }^{3}$ Dep of Radiation Physics, Lund, Sweden

* Corresponding author

from 13th Annual SCMR Scientific Sessions

Phoenix, AZ, USA. 21 -24 January 2010

Published: 21 January 2010

Journal of Cardiovascular Magnetic Resonance 2010, I2(Suppl I):P2I8 doi:I0.I I86/I532-429X-I2-SI-P2 I8

This abstract is available from: http://jcmr-online.com/content/I2/SI/P2I8

(C) 2010 Carlsson et al; licensee BioMed Central Ltd.

\section{Introduction}

Adenosine is a common pharmacological vasodilator agent used in first pass perfusion MRI as well as nuclear cardiology and echocardiography. Coronary flow reserve (CFR) by adenosine is inhibited by caffeine and therefore caffeine abstinence is routinely proscribed in patients. However, the guidelines differ regarding how long abstinence is needed from 12 to 24 hours.

\section{Purpose}

This study was performed to investigate if $12 \mathrm{~h}$ caffeine abstinence is enough to provide maximal coronary flow reserve (CFR).

\section{Methods}

12 healthy individuals ( 5 females, $39 \pm 14$ years) were imaged using a $1.5 \mathrm{~T}$ Philips Intera CV at rest and during adenosine infusion $(140 \mu \mathrm{g} / \mathrm{kg} / \mathrm{min})$ at two occasions, after 12 and $24 \mathrm{~h}$ caffeine abstinence respectively. Coronary sinus flow was measured during breath hold with a phase contrast velocity encoded (PC) TFE sequence with 20 phases per cardiac cycle. Typical imaging parameters were: SENSE factor 2, TE/TR/flip: $3.1 / 4.8 \mathrm{~ms} / 15^{\circ}$, turbo factor 5, spatial resolution $1.2 \times 1.2 \times 7 \mathrm{~mm}$ and VENC 80 $\mathrm{cm} / \mathrm{s}$. CFR was calculated as the ratio between coronary sinus flow/min at adenosine and rest. Cardiac output was measured using PC-MRI of the ascending aorta.

\section{Results}

CFR was higher $(5.4 \pm 1.0)$ at $24 \mathrm{~h}$ caffeine abstinence compared to $12 \mathrm{~h}(4.6 \pm 0.8, \mathrm{p}=0.03)$. In most patients the difference was minimal but in three patients (25\%) the increase in CFR at $12 \mathrm{~h}$ was less than $30 \%$ of that at 24 $\mathrm{h}$ caffeine abstinence. The increase in HR did not differ at $24 \mathrm{~h}(40 \pm 7 \%)$ and $12 \mathrm{~h}$ abstinence $(39 \pm 5 \%, \mathrm{p}=0.62)$ nor did the increase in cardiac output ( $55 \pm 8 \%$ vs. $48 \pm$ $8 \%, \mathrm{p}=0.68$ ). Reported symptoms and the blood pressure reaction did not differ between $24 \mathrm{~h}$ and $12 \mathrm{~h}$ abstinence, Figure 1.

\section{Conclusion}

Twelve hours caffeine abstinence results in a lower coronary flow reserve compared to 24 hours and there is a large inter-individual difference to caffeine abstinence. This needs to be taken into consideration when performing adenosine perfusion imaging studies. 


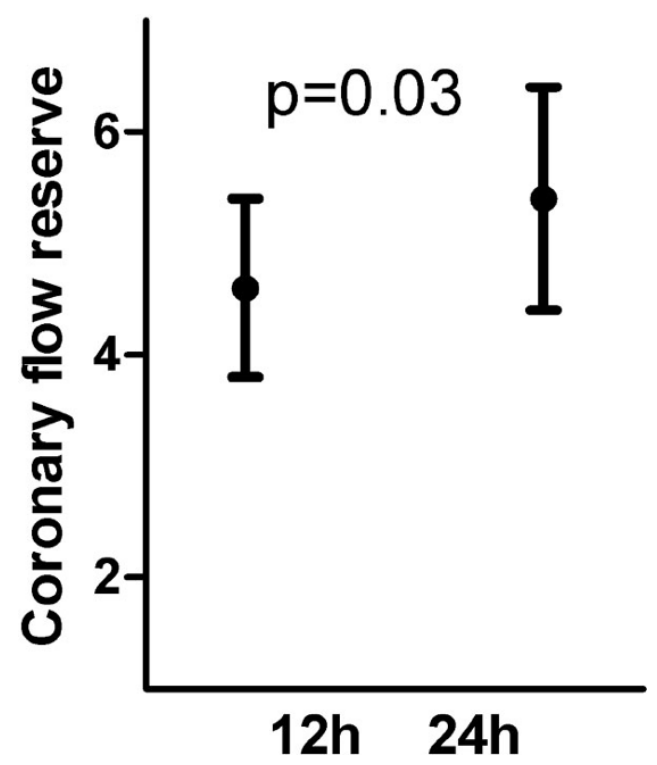

Figure I

Publish with Biomed Central and every scientist can read your work free of charge

"BioMed Central will be the most significant development for disseminating the results of biomedical research in our lifetime. " Sir Paul Nurse, Cancer Research UK

Your research papers will be:

- available free of charge to the entire biomedical community

- peer reviewed and published immediately upon acceptance

- cited in PubMed and archived on PubMed Central

- yours - you keep the copyright 